to the degree of vascularity observed in the trial sections. The frozen sections are treated with the photographic developer until the injected vessels are seen to blacken-a period of about five minutes is satisfactory for D.163 (Kodak). After development, the sections are rinsed well in water, dehydrated, cleared and mounted in D.P.X. Liberal quantities of the mounting medium are required owing to the thickness of the sections. The vessels are revealed in jet black against a very indefinite outline of the general tissue structure.

For thin organs such as the stomach and intestine of small animals, the method can be applied to the study of the vascular network of the various layers. Portions of the fixed tissue are cleared by the method of Spalteholz ${ }^{3}$, after previous development of the silver iodide, and mounted flat on a glass slide. The vascular architecture of the individual layers is observed by variation of depth of focus with the microscope.

R. L. BISHTON

Department of Pathology,

G. H. ROGERS University of Bristol. March 13.

1 Trueta, J., Barclay, A. E., Daniel, P. M., Franklin, K. J., and Prichard, M. M. L., "Studies of the Renal Circulation" (Oxford Blackwell Scientiflc Publications, Ltd., 1947).

${ }^{2}$ Barclay, A. E., Brit. J. Radiol., 20, 394 (1947).

s Spalteholz, K. W "Uber das Durchsichtigmachen von menschlichen und therischen Präparaten" (Leipzig, 1911).

\section{Cause of the Absorption of Water by Submerged Shoots}

OBSERVATIONs made by Dixon and Barlee ${ }^{1}$ recently have inspired a discussion as to the possibility of a transpiration into a saturated atmosphere ${ }^{2,3}$. Dixon and Barlee showed that shoots, placed in a supersaturated atmosphere or being submerged, continue to absorb water for several days. Experiments in pure nitrogen and with narcotics indicate the necessity of respiration. According to the authors it is very probable that respiratory processes supply the leaf-cells with energy to secrete water drawn from the vessels into the leaf spaces. Thoday doubts, however, that water taken up in such amounts could all be retained, and suggests the possibility of transpiration into a saturated atmosphere.

Apparently it has been overlooked by the authors mentioned that in 1935 I published a paper, by which in my opinion a satisfactory elucidation has been given of the causes of phenomena similar to those communicated by Dixon and Barlee.

Considerable absorption of water for several days by cut shoots, submerged or covered with 'Vaseline', was observed; this was especially pronounced in the dark. In the light the absorption proved to be insignificant or even negative. The course of the absorption paralleled exactly the course of the gas exchange. In accordance with Sen and Blackman ${ }^{5}$, who observed an injection of submerged leaves with water, the cause of the movement of sap was attributed to the occurrence of small differences in pressure in the intercellular spaces, resulting from the different solubility of carbon dioxide and oxygen which are exchanged during the respiratory process. It was shown by means of small variations of temperature, alternate bubbling of readily diffusible hydrogen and air that slight differences of pressure from the order of $\mathrm{l}-3 \mathrm{~mm}$. of mercury completely suffice to explain the magnitude of the sap-stream observed. No intake of water was observed when the intercellular spaces were impregnated with water.

The exudated water is retained by the leaves. The weight of a leaf increased by 20 per cent, whereas the volume of the leaf remained the same. In accordance with this the amount of air in the intercellular spaces decreased considerably in the dark, whereas in the light it remained almost constant. Considerable amounts of water are absorbed in this way. A sub. merged shoot with six leaves weighing $6 \cdot 355 \mathrm{gm}$., connected with a potometer, increased $1.032 \mathrm{gm}$. in weight in $86 \mathrm{hr}$; $1.014 \mathrm{gm}$. entered through the cut surface in the same time.

Thus it appears that the continuous movement of sap is a result of respiration. The process proceeds as long as gas exchange is continuing and the intercellular spaces are not completely impregnated with water. Neither active secretion of water by the leaf cells nor transpiration in saturated air play a significant part in this process.

F. VAN DER PAAUW

Agricultural Experiment Station and

Institute for Soil Research T.N.O.,

Gröningen.

April 11.

1 Dixon, H. H., and Barlee, J. S., Sci. Proc, Roy. Dublin Soc., 22, $211(1940)$.

2 Thoday, D., Nature, 164, 541 (1949)

${ }^{8}$ Wilson, K. : Thoday, D., Nature, 164, 1013 (1949).

- Paauw, F. van der, Rec. trav. bot. néerl., 32, 293 (1935).

- Sen, P. K., and Blackman, V. H., Ann. Bot., 47, 683 (1933).

\section{Hypersensitivity and Tumour Development in Potato Tubers in Response to Infections with Phytophthora infestans}

$F_{2}$ forms of a certain cross between a $W$ variety and a common variety of potato, when inoculated with parabiontic strains of blight fungus ${ }^{1}$, were found to produce tumours. These tumours develop on the cut surfaces of tubers which had been covered with a zoòspore suspension of low concentration. They developed after an incubation period of 4-5 days at about $20^{\circ} \mathrm{C}$. It is thought that this mode of reaction is linked with hypersensitivity to the parasite, because such a reaction has not been observed on a hypersensitive ${ }^{2}$ (susceptible) genotype.

The hypertrophic growth of the affected tissues is caused by enlargement and multiplication of the cells which surround those cells that have been destroyed

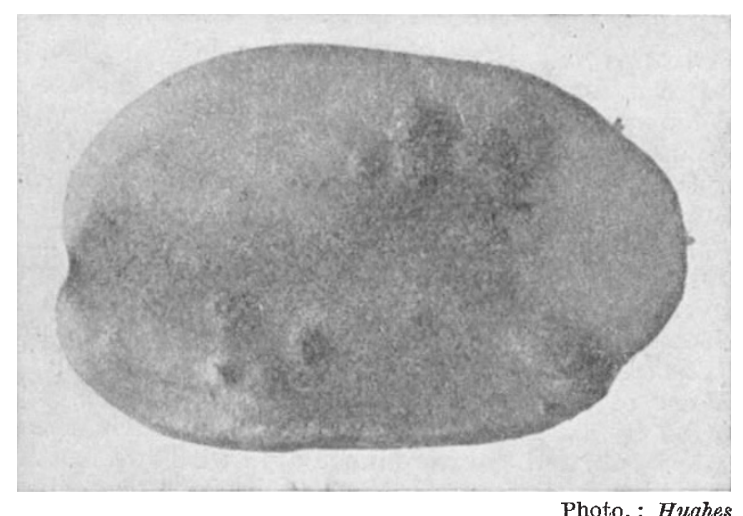

A tuber of an $F_{2}$ seedling showing tumours six days after inoculation with a parabiontic strain of Phytophthora infestans 